\title{
Prevalence of Diarrhoea in Infants and its Relation to Feeding and Weaning Practices
}

\author{
Ramesh Chander, M.D., ${ }^{1}$ Puja Vimesh, M.D., ${ }^{2}$ Shyam Singh, M.Ch. ${ }^{3}$ \\ Departments of 'Family \& Community Medicine Sirte University Libya, ${ }^{2}$ Cardiothoracic Anaesthesia GMC Jammu, and ${ }^{3}$ Cardiovascular \\ \&Thoracic Surgery, Sher-i-Kashmir Institute of Medical Sciences, Srinagar
}

\section{A B S T R A C T}

\begin{abstract}
BACKGROUND: Diarrhoea is one of the major causes of morbidity and mortality in infants in developing countries, because of diverse factors associated with it.

OBJECTIVE: To study the relationship of diarrhoea with feeding and weaning practices.

METHODS: In this Cross-sectional epidemiological study, 704 infants and their mothers were studied for feeding and weaning practices using semi-structured closed ended questionnaire.

RESULTS: Prevalence of diarrhea was observed lowest among exclusive breast fed (3.9\%) and highest among mixed fed including supplementary feeding (15.2\%). Artificial feeding was prevalent in $9.2 \%$. Consumption of leftover food was accompanied by double the prevalence (21.89\%) as compared to those who did not consume such food (10.1\%).

CONCLUSIONS: Education and awareness of mothers regarding breast feeding, can help decrease the prevalence of diarroea in infants and associated morbidity and mortality. JMS 2011 ; 14(1):19-21
\end{abstract}

Key words: Diarrhoea, breast feeding, weaning, infants

Diarrhoea is one of the major causes of morbidity and mortality in infants in developing countries, because of diverse factors associated with it. The study among infants in Jammu city was an endeavour to find out the magnitude of the problem and to study the relationship of diarrhoea with feeding and weaning practices. Lack of proper feeding and weaning practices will lead to malnutrition and malnutrition will give rise to diarrhoea. A vicious cycle is set up between diarrhoea and malnutrition. Oral Rehydration therapy is considered to be the biggest discovery in the management of infantile diarrhoea. ${ }^{1}$

Correspondence and reprint requests to:

Ramesh Chander M.D.,

Head, Deptt. of Family and Community Medicine, Faculty of Medicine, Sirte University, Sirte, Libya.

e-mail: rameshvimesh@yahoo.com

\section{Material and Methods}

\section{Survey population:}

(A) Survey was conducted in infants (b) Mothers of infants

Sample size: Seven hundred and four infants and their mothers were included in the study.

\section{Design of Study}

a. Infants - Cross-sectional epidemiological study of diarrhea, (recommended by $\mathrm{NICD}^{2}$ )

b. Mothers - Study of feeding and weaning practices using oral questionnaire.

Methodology: Mothers of the infants under study were asked the details regarding feeding and weaning practices using semistructured closed ended questionnaire. All information was 
recorded in proforma and data analysed using standard statistical techniques and statistical package for social sciences (SPSS).

Definition of diarrhoea for the purpose of study:

a) Three or more loose watery motions or a single large watery motion in a day. Mother is the best judge for the purpose.

b) If the episodes lasted for less than 14 days, it was termed as acute diarrhoea.

c) If for more than 14 days it was considered as persistent diarrhoea.

d) If blood and mucus was present then it was labelled as dysentery.

e) If vomiting was also present along with diarrhoea it was termed as "Gastro-enteritis. All the cases falling under the heading (a) to (c) and (d) were considered as "diarrhoea cases".

\section{Results and Discussion}

A total of seven hundred and four infants were surveyed, eighty four were detected having diarrhoea with a prevalence rate of $11.60 \%$. This population formed $7.45 \%$ of total population surveyed for detecting prevalence of diarrhoea in children under sixyears of age.

Malhotra $e t a l^{3}$, observed the prevalence of diarrhoea in infants to be $30.85 \%$, Vandana et $\mathrm{l}^{4}$, noted it as $20.3 \%$ while as environment; while the same factors were either missing or less practised in infants of 6-12 months of age. In addition, wrong weaning practices and higher exposure to external hazardous environment could be the factors leading to higher prevalence rate in second half of infancy.

Jinadu et al observed highest prevalence in 0-11 months of age group. Ministry of Health and Family Welfare government of India (CDD programme plan operation 1982-83) showed higher prevalence of diarrhoea in 3-36 months of age with peak at 6-7 months of age. Popkin et al in a study in urban areas of Cibu found prevalence of diarrhoea to be ranging from $7.2 \%$ to $12.7 \%$ in 0-4 months of age and $20.4 \%$ at 6 months of age. Waheed et al revealed highest prevalence in 6-14 months of age.

Infants feeding practices of mothers have strong bearing on diarrhea. Correct practices on one hand have beneficial effect by preventing malnutrition, while wrong behaviors especially faulty weaning practices expose them to harmful environmental hazards. Therefore most effective measures to prevent malnutrition and diarrhoea in infants is exclusive breast feeding for first 6 months and correct weaning practices thereafter.

In the current study it was seen that exclusive breast fed, exclusive bottle fed, mixed and mixed plus supplementary feeding were accompanied by diarrhoeal prevalence of $3.9 \%$, $9.2 \%, 10.6 \%$ and $15.2 \%$ respectively among the infants (Table 2 ).

Moreover there was no significant association of weaning the infant at the age of 4-5 months or late on diarrhoeal prevalence (Table 3), but giving left over feed was associated with

Table 1: Prevalence of diarrhoea in infants

\begin{tabular}{|c|c|c|c|c|c|c|c|c|c|}
\hline \multirow{3}{*}{$\begin{array}{l}\text { Age group } \\
\text { (months) }\end{array}$} & \multicolumn{3}{|c|}{ Male } & \multicolumn{3}{|c|}{ Female } & \multicolumn{3}{|c|}{ Total } \\
\hline & $\bar{N}$ & Diarrhoeal & Prevalence $(\%)$ & $\bar{N}$ & Diarrhoeal & Prevalence $(\%)$ & $\mathrm{N}$ & Diarrhoeal & Prevalence(\%) \\
\hline & & cases & $(\%)$ & & cases & & & cases & \\
\hline $0-2$ & 42 & 2 & 4.76 & 55 & 6 & 10.91 & 97 & 8 & 8.25 \\
\hline $2-4$ & 50 & 3 & 6.00 & 40 & 4 & 10.00 & 90 & 7 & 7.78 \\
\hline $4-6$ & 61 & 4 & 6.56 & 49 & 6 & 12.24 & 110 & 10 & 9.09 \\
\hline $6-8$ & 80 & 8 & 10.00 & 68 & 10 & 14.71 & 148 & 18 & 12.16 \\
\hline $8-10$ & 78 & 12 & 15.38 & 51 & 8 & 15.69 & 129 & 20 & 15.50 \\
\hline $10-12$ & 72 & 10 & 13.89 & 58 & 11 & 18.97 & 130 & 21 & 16.15 \\
\hline Total infants & 383 & 39 & 10.18 & 321 & 45 & 14.02 & 704 & 84 & 11.60 \\
\hline
\end{tabular}

N: No. surveyed

Saran et al found prevalence of diarrhoea in infants in Varanasi to be $52.3 \%$.

The prevalence of diarrhoea in infants was found to be 11.6 $\%$.(Table 1) It was observed that infants under 6 months of age suffered less (Prevalence $8.41 \%$ ) in comparison to infants of 6-12 months of age (Prevalence 14.49\%). The peak prevalence was $16.15 \%$ in $10-12$ months of age and lowest of $7.78 \%$ in $2-4$ months of age group.

Lower suffering rate in first half of infancy could be due to protective effect of maternal derived immunity, exclusive breast feeding had less chances of exposure to deleterious external

Table 2: Association of feeding practices with diarrhoea in infants

\begin{tabular}{|c|c|c|c|c|c|}
\hline \multirow[t]{2}{*}{ Feeding Practices } & \multicolumn{2}{|c|}{ Diarrhoeal Infants } & \multicolumn{2}{|c|}{ Non-diarroeal Infants } & \multirow[t]{2}{*}{ Total } \\
\hline & No. & $\%$ & No. & $\%$ & \\
\hline i. Breast Feeding & 4 & 3.9 & 99 & 96.1 & 103 \\
\hline ii. Bottle Feeding & 7 & 9.2 & 69 & 90.8 & 76 \\
\hline iii. Breast \& Bottle Feeding & 16 & 10.8 & 135 & 89.4 & 151 \\
\hline $\begin{array}{l}\text { Iv. All types inclusive of other } \\
\text { vegetable \& cereal supplement }\end{array}$ & 57 & 15.2 & 317 & & 374 \\
\hline Total & 84 & 11.9 & 620 & 88.1 & 704 \\
\hline
\end{tabular}


higher prevalence $(21.89 \%)$ as compared to other comparative group with prevalence $10.08 \%$ (Table 4).

Table 3: Weaning practices (among infants 5-12 months of age) and diarrhoea

\begin{tabular}{lccc} 
& \multicolumn{3}{c}{ Number of infants } \\
\cline { 2 - 4 } Weaning & Suffered & Not suffered & Total \\
EarlyLate & $28(11.96 \%)$ & 206 & 234 \\
& $41(14.48 \%)$ & 242 & 283 \\
\hline Total & $69(13.34 \%)$ & 448 & 517 \\
\hline
\end{tabular}

$\chi^{2}, 0.674 ; \mathrm{df}, 1, p<0.05$ (Significant)

Table 4: Consumption of left out over food and diarrhoea

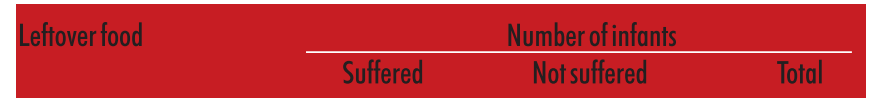

\begin{tabular}{lccc} 
Consumed & $37(21.89 \%)$ & 132 & 169 \\
Notconsumed & $45(10.08 \%)$ & 401 & 446 \\
\hline Total & 82 & 533 & 615 \\
\hline
\end{tabular}

$\mathrm{X}^{2}, 14.76 ; \mathrm{DF}, 1 ; \mathrm{P}<0.001$ (Highly Significant)

Kumar $\mathrm{V}$ et al in their study found that breast fed had half the diarrhoeal prevalence as compared to bottle fed and mixed fed infants.

Jaiswal has also shown beneficial effects of breast feeding on diarrhoeal orbidity. But, artificial feeding and mixed feeding had similar diarrhoeal morbidity in their study group of preschool children. It was observed that beneficial effect of exclusive breast-feeding were offset by introduction of supplementary feeding, presumably because of associated poor hygienic behavior.

Popkin et al studied the effect of breast feeding on diarrhoeal morbidity at 2 months, 4 months and 6 months in urban area of Cibu. The prevalence of diarrhoea in exclusive breast fed children was $4.6 \%, 13 \%$ and $13.2 \%$ respectively. In non-breast fed $74.4 \%, 15.9 \%$ and $23.7 \%$ respectively and in mixed fed infants $5.6 \%, 11.6 \%$ and $19.9 \%$ respectively.

Other researchers in periurban community of Guinea Bissau revealed higher rate of diarrhoeal attacks among bottle-fed as compared to breast-fed infants. Breast feeding and correct weaning practices helped in reducing morbidity and mortality among infants to a great extent. Nutritional status and diarrhoea operate in a synergistic manner; a bi-directional causal relationship exists, leading to a vicious circle of diarrhoea-malnutritiondiarrhea.

\section{Conclusions}

Feeding practices showed lowest prevalence of diarrhoea among exclusive breast fed (3.9\%) and highest among mixed fed including supplementary feeding (15.2\%). Artificial feeding showed prevalence of $9.2 \%$. Consumption of left over food was accompanied by double the prevalence $(21.89 \%)$ as compared to those who did not consume such food (10.1\%). Education and awareness of mothers regarding breast feeding, can help decrease the prevalence of diarroea in infants and associated morbidity and mortality.

\section{References}

1. WHO, UNICEF. "Oral Rehydration Salts: Production of the new ORS" (PDF)http:/libdoc.who.int/hq/2006/ WHO_FCH_06.1.pdf

2. NICD-Publication 1984, Manual of epidemiological surveillance procedure for selected diseases: Epidemiological surveillance procedure for diarrhoea disease, 12-30.

3. Malhotra Prabha, Prasad BG. A study of morbidity among children below 5 years of age in an urban area in Delhi. Ind MedRes 1966;54(3):285.

4. Vandana Sen, Nee Sharma, Sharma R and Purhohit BK. Morbidity pattern among children below 5 years in urban Sindhi community. Indian J Pediat 1978;45:325.

5. Saran M, Verma BL, Kumar A. An epidemiological study of diarrhoea amongst children under 5 years in a slum community of Jhansi. Indian Pediat 1979;16(1):33.

6. Jinadu MK, Olusi SO, Agunji, Fabiyi AK. Childhood diarrhoea in rural Nigeria, Studies on prevalence, mortality and socio-environmental factors.J Diarrhoeal Dis Research 1991;9(4):323-7.

7. Popkin B, Buscoe J, Van Deislica J. Drinking water quality, sanitation and breast feeding, their interaction effects on infant's health.WHOBulletin OMS 1994;71.

8. Waheed Abdullah Millet, Sufian Mohammed Elassouli. Epidemiology of diarrhoea in 2 major cities in Saudi Arabia. JCom Dis 1995;27(2):84-91.

9. Kumar V, Kumar L, Divedi P. Morbidity Related feeding patterns in privilege urban and under privileged rural infants. Indian Pediatr 2005;15:743. 